\title{
White Water Kayaking Risk: Malaysian Perspective
}

\author{
Jaffry Zakaria, Mazuki Mohd Yasim, Md Amin Md Taff, Benderi Dasril, Mirza Azny Mustafa \\ Faculty of Sport Science \& Coaching, Sultan Idris Education University, Tanjung Malim, Malaysia \\ Email: jaffry@fsskj.upsi.edu.my
}

How to cite this paper: Zakaria, J., Yasim, M.M., Taff, M.A.M., Dasril, B. and Mustafa, M.A. (2017) White Water Kayaking Risk: Malaysian Perspective. Open Access Library Journal, 4: e3168. https://doi.org/10.4236/oalib.1103168

Received: October 24, 2016

Accepted: March 4, 2017

Published: March 7, 2017

Copyright $\odot 2017$ by authors and Open Access Library Inc.

This work is licensed under the Creative Commons Attribution International License (CC BY 4.0).

http://creativecommons.org/licenses/by/4.0/ (c) (†) Open Access

\begin{abstract}
White water kayaking is the fun sport on fast moving water, typically call white water river. The element of fun and challenge has attracted many people to join this adventure sports in Malaysia. This study examined the risk in adventure sport tourism by white water kayakers in Malaysia. The objective of this study is to reveal the injuries suffered by whitewater kayakers during activity. This 2013 survey will be described using descriptive data only. The survey forms were distributed via kayak clubs and associations under the auspices of the Malaysian Canoe Association (MASCA). The survey asked respondents about their previous injuries during white water kayaking activities. All the data concerning to age, sex, experience and ability was collected from them. A total of 217 respondents provided feedback on this survey. Of the total 217, about 186 respondents experienced injuries during an activity, while the rest did not suffer any injuries while they were kayaking. The result showed only $41 \%$ seeks medical attention after injury. These whitewater kayaking activities require physical exertion as well as emotional and mental stability. Good practise and skill can help kayakers avoid injuries and accident during paddling session. This sport has been developing and growing each year. Future studies can also be done by looking for new discipline in white water which is "playboating" which may find different risk and injury.
\end{abstract}

\section{Subject Areas}

Sports Science

\section{Keywords}

Injuries, Malaysia, Risk, Adventure Sport, White Water Kayaking

\section{Introduction}

White water kayaking is a very unique activity in which people have navigate or 
playing in the small boat, maneuvering the river and play with the rapids and waves. Wearing a spray cover is most important to avoid water from getting into the boat. High skill techniques such as rolling can help kayakers to be more confident when they capsize because they will be able to flip back in normal position. The suitable paddling technique is very useful for kayakers to survive during paddling along the river. The river difficulties are rated from grade I to grade VI, which is from the easy level to the most difficult.

White water kayaking is one of the most popular and potential adventure sports after rafting activities in Malaysia. There are more than five rivers that most challenging in Malaysia that can be carried out this activity. Some of the river located in peninsular Malaysia and also Sabah and Sarawak states. Through attractions besides its clear water river, indirectly help the industry grow among tourists. It has become a popular product in adventure sport tourism where images and videos being used in advertisement such as sports merchandise, drinks, electrical gadgets as well as for education purposes. Even though kayaking is usually considered as a dangerous sport, not much is actually known about the risks and the types of injuries often occur. As the popularity of white water kayaking increases, numbers of injuries involving this activity will also increase from time to time (Table 1).

The present study intended to acquire types of injuries often experienced by white water kayakers in Malaysia. By identifying the factors involved in injuries, it may be possible to modify risks and reduce injuries among the kayakers.

\section{Data Analysis}

The respondents where white water kayakers in Malaysia who response either online survey or via face to face. The survey forms were distributed via kayak clubs and associations, located in different states in Malaysia (Perlis, Kedah, Pulau Pinang, Perak, Kuala Lumpur, Selangor, Pahang, Melaka, Negeri Sembilan, Johor, Kelantan, Terengganu, Sabah and Sarawak). These clubs and associations are under the auspices of the Malaysian Canoe association (MASCA). Most respondent did the surveys online.

The data based on previous five years injuries were collected in 2013. Notifications of the survey web were made through the link of the Malaysian Canoe

Table 1. Scale of river difficulty.

\begin{tabular}{|c|c|}
\hline River Grading & Explanation \\
\hline Grade I & No rapids and smooth flowing water (more to flat water) \\
\hline Grade II & Some rough water and the line is easy to see or pursue \\
\hline Grade III & $\begin{array}{l}\text { Very safe for larger rafts: kayakers and canoeist should have good rolling and } \\
\text { self-rescue skills }\end{array}$ \\
\hline Grade V & $\begin{array}{l}\text { For experience paddlers: the route through the rapids may require quick } \\
\text { maneuvering }\end{array}$ \\
\hline Grade IV \& VI & $\begin{array}{c}\text { For advanced paddlers and team of experts: scouting the rapids may be required } \\
\text { and there may be hidden hazards which require precise maneuvering and taking all } \\
\text { safety precautions }\end{array}$ \\
\hline
\end{tabular}


Association (MASCA) homepage, postings in white water group, via blog and white water kayaking facebook group. A brief story and introduction about the survey were linked to the website. All data were collected from June until November 2013. This study only analyses the result from the white water kayakers at the selected venues only. All data was analyzed using SPSS version 20.

\section{Result and Discussion}

Data were collected from 217 white water participants. Of these, about 186 respondents experienced injuries during an activity while the rest did not suffer any injuries while they were kayaking. From the study, most kayakers were injured when they were in the medium water flow (48\%), followed by high water flow (38\%) and low water flow (7\%). Table 2 shows the injuries by area.

The most difficult rapid where injuries often occurred was Grade III rapid (41\%) followed by Grade II rapid (34\%) and Grade I rapid (7\%). Table 3 shows injuries by rapids.

Most injuries occurred while kayaker was in the river, with $76 \%$ occurring while in the boat compare to $17 \%$ while walking or portaging and $7 \%$ while swimming. The most common types of injury were confusion (31\%), sprain (24\%), dislocation (17\%), tendinitis (10\%), abrasion (10\%), fracture (3\%) and near drowning (3\%). The result also showed only $41 \%$ seeks medical attention after injury. Table 4 shows the types of injuries among respondent.

Table 2. Injuries by area.

\begin{tabular}{ccc}
\hline No. & Injuries by Area & Percentage of injuries by area (\%) \\
\hline 1$)$ & High water & $38 \%$ \\
$2)$ & Medium water & $48 \%$ \\
$3)$ & Low water & $7 \%$ \\
\hline
\end{tabular}

Table 3. Injuries by rapids.

\begin{tabular}{ccc}
\hline No. & Grade of Rapids & Percentage of injuries (\%) \\
\hline 1$)$ & Grade I & $7 \%$ \\
$2)$ & Grade II & $34 \%$ \\
$3)$ & Grade III & $41 \%$ \\
\hline
\end{tabular}

Table 4. Type of injuries.

\begin{tabular}{ccc}
\hline No. & Type of Injuries & Percentage (\%) \\
\hline 1$)$ & Confusion & $31 \%$ \\
$2)$ & Sprain & $24 \%$ \\
$3)$ & Dislocation & $17 \%$ \\
$4)$ & Tendinitis & $10 \%$ \\
$5)$ & Abrasion & $10 \%$ \\
$6)$ & Fracture & $3 \%$ \\
$7)$ & Near Drowning & $3 \%$ \\
\hline
\end{tabular}


The present study provides important new information on kayaking injuries. According to [1], the grading and definition of sports injuries can be performed from various perspectives. This study focused on the nature and types of the injury as well as types of river difficulty where the injuries often occurred.

Finding of this study showed that most injuries were due to kayakers using rivers above their skill level. Most injuries occurred when kayakers were in the medium water level rivers compared to high and low water level. This usually happened when novice kayakers used the medium water level rivers to do kayaking. As a beginner, they should always start with low water level rivers. This finding is similar to [2] where highest injuries were observed when kayakers were having their activities in the medium water level rivers. Meanwhile, fewer injury were observed in the high water level rivers due to the location risks and the difficulties of the route. Most kayakers usually prefer to do kayaking in the lower risks rivers such as medium and low water level rivers. Only expert kayakers will use the more difficult rivers, and therefore, the injuries were less reported. Therefore, it is important to ensure kayakers stay within their skill level to ensure the safety and at the same time reduce injuries.

Comparing to the types of rapids, Grade III rapids showed higher risks compared to Grade II and Grade I. Generally, based on the scale of difficulty in international rivers, river rapid Grade I usually has slow and small current, easy to navigate. It is considered safe and rescue activities are easy to be implemented. In the meantime, Grade II rapids are straight and very accessible. There will be small waves that cause water ripples along the obstacles such as fallen trees and twigs. The kayaking activities in this river are at intermediate and moderate safe level with less close monitoring needed.

Conversely, water ripples in grade III rapids are quite strong and the obstacles are more compared to Grade I and II. The current flow in these rapids is uneven and evolving. Kayakers require high skills to ride in these rapids. Review on impassable rapids is importantly required prior to making a decision to go through it. Rapids in this grade are very difficult to be predicted. Kayakers must be experienced kayakers in Grade II river rapids before pursuing into Grade III rapids.

Numbers of injuries in the kayak is extremely high when compared to while carrying or portaging the kayak or while swimming. This result is in support with the findings by [2] where $87 \%$ of injuries occurred while the kayakers were in the boat comparing to $8 \%$ while swimming and $5 \%$ while carrying the kayak to or from the river, or around a difficult rapid. Compared to the present study, [3] in his study found higher incidence of shoulder dislocations (45\%) and near drowning (11\%). The risk of injury is much higher when the kayaker tried to reverse its kayak while kayaking in a white water river. Among the injuries were head injuries, sprains, dislocations, tendinitis, abrasion, fracture and near drowning. This happened when the kayak over turned, the kayakers need extra time to do rolling technique to come back to the original position. Longer time is needed to perform the rolling technique and therefore the kayakers were exposed to head injuries as they might hit the rocks as the water is always moving. 
Fortunately, helmets are universally accepted among kayakers. Although significant head injuries appear to be uncommon in kayaking [4] [5] and [6], when they occur in kayaking, the outcome can be catastrophic because they can lead to drowning [7] [8] [9] [10] reported that $33 \%$ of rafting injuries were to the face and some kayaker have taken to wearing the helmets with built in or add on face masks.

The occurrence of injuries to the upper extremity may be explained by the fact that it is very exposed and provides most of the muscle for kayaking, making it vulnerable to overuse, traumatic stress (transmitted force) and impact injuries. Previous studies have also noted the majority of such injuries [1] [4] [6] and paddling instructors focus on technique as being critical for preventing or at least minimizing upper extremity injuries such as tendinitis and shoulder dislocations. Safety measures need to be taken seriously in order to limit injuries while kayaking from happening.

\section{Conclusions}

All the risks such as fast moving rapids, flash floods, falling and rolling rocks, capsize, bitten by wild insects and animals as well as unpredictable forces of nature including weather that may change to extreme conditions without sign, are the contributors to the occurrence of the injuries. In future, all the data gathered in this research can apply to give some information to the community. They can get the important information before they make a decision to paddle with selected white water rivers.

Improving paddling technique may be one approach to limiting injuries such as sprains, dislocation, tendinitis, torn ligament or muscles, neck or spinal injuries, almost drowning and many others. These injuries often occur due to poor paddling technique. White water kayaking activities requires physical exertion as well as emotional and mental stability. Good practice and skill can help kayakers to avoid injuries and accident during paddling. This sport has been growing and developed each year. Studies looking for new discipline in white water such as "playboating" which may find different type of risk and injury could also be done in future.

\section{References}

[1] Finch, C. (1997) An Overview of Some Definitional Issues for Sports Medicine Injury Surveillance. Sport Medicine, 24, 157-163. https://doi.org/10.2165/00007256-199724030-00002

[2] Fiore, D.C. and Houston, J.D. (2001) Injuries in Whitewater Kayaking. British Journal Sports Medicine, 35, 235-241. https://doi.org/10.1136/bjsm.35.4.235

[3] Kizer, K. (1987) Medical Aspects of White-Water Kayaking. Physician and Sport medicine, 15, 128-137. https://doi.org/10.1080/00913847.1987.11702036

[4] Burrel, C. and Burrel, R. (1982) Injuries in Whitewater Paddling. Physician and Sport Medicine, 10, 119-124.

[5] Kizer, W. (1987) Medical Problems in Whitewater Sports. Clinical Sports Medicine, 6, 663-669. 
[6] Wallace, D. (1992) Dancing with Risk: The Result of the 1991 AWA Close Calls and Serious Injury Study. American Whitewater.

[7] Walbridge, C. (1986) American Canoe Association River Safety Report 1986-1988. American Canoe Association, Newington.

[8] Walbridge, C. (1996) American Canoe Association River Safety Report 1992-1995. Menasha Ridge Press, Birmingham.

[9] Whisman, S. and Hollenhorst, S. (1999) Injuries in Commercial Whitewater Rafting. Clinical Journal of Sports Medicine, 9, 18-23. https://doi.org/10.1097/00042752-199901000-00004

[10] Shephard, R.J. (1987) Science and Medicine of Canoeing and Kayaking. Sports Medicine, 4, 19-33. https://doi.org/10.2165/00007256-198704010-00003

Submit or recommend next manuscript to OALib Journal and we will provide best service for you:

- Publication frequency: Monthly

- 9 subject areas of science, technology and medicine

- Fair and rigorous peer-review system

- Fast publication process

- Article promotion in various social networking sites (LinkedIn, Facebook, Twitter, etc.)

- Maximum dissemination of your research work

Submit Your Paper Online: Click Here to Submit

Or Contact service@oalib.com 